\title{
Exploring the bi-directional relationship of stock return and sustainability performance through the sustainability risk lens (case of Indonesia)
}

\author{
Sita Deliyana Firmialy*; Sudarso Kaderi Wiryono; Yunieta Anny Nainggolan
}

School of Business and Management, Institut Teknologi Bandung, Indonesia

*To whom correspondence should be addressed. Email: sita.deliyana@sbm-itb.ac.id

\begin{abstract}
Sustainability investing has been evolved significantly since the last decade. The inclusion of social, environmental, and economic dimension into the portfolio screening criteria is stated as an essential strategy to increase the firms' financial performance. However, previous empirical evidence has gained a mixed result on this issue (i.e. positive, negative, and insignificant). This study contributes to the discussion by offering result on the heterogeneous effect of sustainability performance to the stock return, specifically through the sustainability risk lens. Sustainability risk is related to firm sustainability concern of not being able to perform in a "sustainable manner", thus related directly to the inefficiency within the firms, as well as the firms' idiosyncratic risk. Uniqueness contribution of this study is by offering the analysis in a disaggregated ways (i.e. separately examines the relationship between each sustainability performance dimensions and stock return), within portfolio level. Using large size of cross-sectional data (more than 400 companies over two years span of time) covered all non-financial sectors listed in the Indonesia Stock Exchange (IDX), we are able to confirm the notion of heterogenous sustainability performance within Indonesian firms. We also found evidence on the positive direction of an increase of social and economic performance to stock return. Meanwhile, environmental sustainability performance shows the contrast direction.
\end{abstract}

Keywords: Financial Performance, Indonesia, Sustainability Investing, Sustainability Performance, Stock Return, Sustainability Risk

JEL Classification: G11, G32, M14, Q56

\section{INTRODUCTION}

The trends of sustainability investing have been growing nowadays aligned with the increased concerns of of investors on companies' essential ESG issues. Sustainability investing, or socially responsible investing (SRI), often are stated interchangeably with the concept of Corporate Social Performance (CSP), Corporate Social Responsibility (CSR), or Shared Value (SV). In this paper, we define the concept of sustainability investing as the way of investing with screening methodology focused on not only the financial performance but also on the social, environmental and economic performance of the firms. Related to this definition, we used the term of Sustainability Investing (SI), rather than Corporate Social Performance (CSP), Corporate Social Responsibility (CSR) or Socially Responsible Investing (SRI). 
The screening criteria in SI focused on two ways, firstly refer to positive screening whereas tilting the portfolios selection to the most responsible ones, and secondly, refer to a negative screening whereas directly excluded firms with the least responsible performance from the portfolios selection process. In this way, theoretically, SI may be able to decrease risk from the portfolio, by carefully selecting firms with better performance. In this sense, SI could increase the portfolio Sustainability Performance (SP), and along with that decrease the sustainability risk. Consequently, in this study, we will use the term SP afterwards to represent the Sustainability Performance of the firms, rather than CSP or CSR.

Research on the relationship between sustainability and financial performance, specifically on portfolios performance returns, has been mixed. Fulton, Kahn \& Sharples (2012) noted on the ability of firms with higher CSR performance to exhibit market outperformance. However, further strategy to completely "dispose" controversial firms from the portfolio, has yielded negative results against the market.

Fulton, Kahn \& Sharples (2012) result are aligned with the findings of Statman \& Glushkov (2009). In their research, Statman \& Glushkov (2009) stated on the negative aspect of social sustainability investing, that are more expensive, rather than the traditional investing. They confirmed the superior performance of firms with higher CSR scores. However, the gains are shunned off with the cost of excluding the negative CSR-related stocks.

The controversies related to the topic further move to the focused on negative screening criteria(s) only and definite screening criteria(s) only. Fabozzi, Ma, \& Oliphant (2008) confirmed the dominance power of controversial stocks to overpower the market. Their result was strengthened with further evidence gained by Hong \& Kacperczyk (2009), that stated on the extreme performance of sin stocks as an antagonistic result of ethical investors behaviour. In their study, they stressed the direct the effect of "carefully excluding" the sin stocks in their portfolio screening criteria resulted in higher performance of the sin stocks itself. Positive screening criteria focus on the implication of the inclusion of firms with higher social responsibility scores to the portfolios screening process. The previous study by Dravenstott \& Chieffe (2011) found evidence on the superior performance of high-socially-responsible-stocks portfolios in defeated the market.

Regarding the notion of the relationship between SI and Firm Risk, or CSR and Firm Risk, Boutin-Dufresne \& Savaria (2004), Mishra \& Modi (2013), De \& Clayman (2015) found the evidence on the negative relationship between financial performance of portfolios with high SRI scores and their idiosyncratic risk.

However, Cheng, Ioannou \& Serafeim (2014) add more to the debate by provide the positive evidence on the relationship of positive relationship between social performance and financial performance. They stated that firms with excel level of socially responsible performance are able to maintain a good relationship with their stakeholders thus enable the firms to reduce the agency costs and lower information asymmetry risk.

Meanwhile, Boaventura, Da Silva \& De Mello (2012) found an evidence of no significant relationship between companies social performance and their financial performance in the short term. However, they found positive evidence of significant relationship only in the long term.

Overall, empirical evidence on the relation between SI and financial performances of the firm lead to inconclusive results, namely positive, negative and no relationship at all. However, investigation on the capability of SI to decreasing 
portfolios risk yielded more conclusive result. A negative relationship has been confirmed on the relationship between firm social sustainability and their risk, and higher social sustainability scores are correlated with a lower level of firm risk.

In this study, we investigated the leveraging effect of sustainability screening portfolios in reducing portfolios risk within the Indonesian context. Specifically, we adopted the methodology developed by Brammer, Brooks \& Pavelin (2006) by investigating the disaggregated effect of Social-Environmental-Economic performances of the firms to their financial performances. In their research, they construct several types of portfolios based on firms' CSR scores and holding it for one or two-year holding period. In their study, they found pieces of evidence on the negative relationship between CSR scores and stock return, in a portfolio level.

The same evidence found by Galema, Plantings \& Scholtens (2008). In their study, they stated that within social sustainability, only employee relation resulted in a significant positive effect on companies' financial performance. The study fills the gap within the theoretical context by providing evidence for the relationship between sustainability and financial performance in the portfolio level. Specifically, the main contribution of this study is related to the examination on the disaggregating effect of each component of sustainability performance to the firm financial performance.

Uniqueness contribution of this study is by offering the analysis in a disaggregated ways (i.e. separately examines the relationship between each sustainability performance dimensions and stock return), within portfolio level. The second contribution of this study lies within the use of the large size of cross-sectional data (more than 400 companies over two years span of time) covered all non-financial sector listed in the Indonesia Stock Exchange (IDX). In other words, we performed sectoral level on the relationship of the sustainability performance of the firms to the stock return.

The article is organized as follows, Theoretical Framework is explained in the second section, and Methodology in the third section. The fourth section focused on the Empirical Findings and Discussion, lastly closed with Conclusion in the last section.

\section{LITERATURE REVIEW}

Large body gap of the literature focused on investigating the association between sustainability investing and corporate financial performance. Mixed evidence was gathered and yielded non conclusive results, namely positive relationship (Orlitzky Schmidt \& Rynes, 2003; Fauzi \& Idris, 2009; Rais \& Goedegebuure, 2009); and negative or insignificant relationship (Ullman, 1985; Vance, 1975; Alexander \& Buchholz, 1975; Brammer, Brooks \& Pavelin, 2006).

Further direction of the sustainability and financial performance focused on the identification of critical points that enable companies to benefit from Sustainability Investing in the capital market. For example, Cheng, Ioannou \& Serafeim (2014) confirmed the evidence of more available access to finance for socially responsible firms. They stated that firms with excel level of socially responsible performance are able to maintain a good relationship with their stakeholders thus enable the firms to reduce the agency costs and lower information asymmetry risk.

Dhaliwal, Oliver, Tsang \& Yang (2011) gave valid evidence on the positive signal gained from companies initiation to disclose their sustainability performance or CSR performance, on firms' cost of equity capital. In this study, they confirmed the behaviour of firms that are "less socially responsible" as more proactive toward their CSR information disclosures strategy compared to their peers that behaved in more 
responsible ways. In this sense, the study confirmed the notion of companies with higher CSR performance and reduced level of cost of equity capital.

Related to the concept of a relationship between CSR and firms' financial risk, Jo \& $\mathrm{Na}$ (2012) reported the negative direction between CSR and firm risk. They mentioned the extreme level of a negative relationship between firm CSR performance and their risk in the controversial industry sectors.

Their results are aligned with the result of Fabozzi, Ma \& Oliphant (2018) and Hong \& Kacperczyk (2009). In their study, they confirmed the superior performance of controversial stocks to overpower the market. Hong \& Kacperczyk (2009) stated on the extreme performance of sin stocks as an antagonistic result of ethical investors behaviour. In their study, they stressed the direct effect of "carefully excluding" the sin stocks in their portfolio screening criteria resulted in higher performance of the sin stocks itself.

Numerous studies have been focused on the investigation of firms' sustainability and financial performance, both in the developed and developing countries. For example, within the area of developing country, Brammer, Brooks \& Pavelin (2006) examine the relationship between CSP and stocks returns, as a market-based measure for CFP, in a portfolio level. They found that there is negative significance between CSP and stocks returns, and considerably abnormal return can be gained from holding least-socially responsible stocks.

Galema, Plantings \& Scholtens (2008) examine the effect of SRI on stock returns from the DataStream data based by conducting three analyses using the KLD scores from the period of 1992-2006. They found that SRI stocks do not generate risk-adjusted excess returns, and employee relationship is the only SRI dimension that has a significant positive effect on monthly excess returns.

Artiach, Lee \& Nelson (2010) investigate factors that drive high levels of CSP as proxies by the membership of the DJSI. They found that leading CSP firms are more profitable when compared with conventional firms, and they are most likely the largest firms in each industry. Boaventura, Da Silva \& De Mello (2012) focus on the aspects of the relationship between CSP-CFP. They found that long term institutional investment is positively related to CSP, there is no significant relationship between short term investors and CSP, disaggregation of CSP into its constituent components suggest that the pattern of institutional investment is also related to the form which CSP takes.

In developing countries, several pieces of evidence were gathered as well. For example, Fauzi, Mahoney \& Rahman (2007) examine the relationship between institutional ownership and CSP for Indonesian companies. They found that there is no significant relationship between institutional ownership and CSP for Indonesian companies. Most institutional ownership in Indonesia does not include CSP as part of their investment decisions. The paper also suggests measuring CSP over several years, and the paper also suggests combining content analysis with a qualitative approach to improve research results.

In their other research paper, Fauzi \& Idris (2009) examine the difference of CSP between state-owned and private companies in Indonesia, and also to analyze the correlation between the CSP and CFP by using company size and institutional ownership as a control variable. They found that there is no significant mean difference of CSP between state-owned and private-owned companies in Indonesia. They also recommend using a longitudinal approach as an alternative to cross-sectional approach and extend CFP measure to market-based measure. Correlation test show there is no association between CSP and CFP in Indonesian state-owned and private companies. 
Rais \& Goedegebuure (2009) examine stakeholder relations as a reliable measure of CSP, and its impact on firm performance and firm competitive position. They found that stakeholder-oriented CSP adds significant effect to financial performance and competitive position. Firms that apply CSP strategies are able to do their businesses more effectively. Fauzi \& Idris (2009) measure CSP, CFP, business environment, strategy, organization structure, and control system. They found that under slack resources theory and good management theory, the study found positive relation between CSP-CFP; and the CSP-CFP link under slack resources theory is stronger than CSP-CFP link under the good management theory. They recommend further research to study on the impact of contextual variables of corporate performance on CSR as a base to develop TBL (triple bottom line) based CSR reporting in Indonesia.

Boaventura, Da Silva \& De Mello (2012) focus on investigating the relationship between CFP and CSP, with main theoretical covered the stakeholder theory, the relationship between CSP-CFP, good management theory and slack resources theory. They found that the main result in the theoretical field reinforce the proposed positive relationship between CSP-CFP and good management theory and demonstrate a deficiency in the explanation of the time lag in the causal relationship between CSPCFP, as well as deficiencies in the description of the CSP construct. For further research, this paper gave the recommendation to research the temporal lag in the causal relationship between CSP and CFP and the possible reasons why the positive association between CSP and CFP has not been assumed in some empirical studies.

Odia \& Imaghe (2015) examine the relations among corporate social and environmental disclosure, social and environmental performance and financial performance in Nigeria based on simultaneous equation approach. They found that good social and environmental performance is significantly and positively associated with good economic performance, social and environmental disclosure. They also found that the negative and significant association between financial performance and social and environmental disclosures indicate that economically viable companies are varied and reluctant to make substantial social and environmental disclosures. Future recommendation from this paper suggests taking data sample from a corporate annual report, as this may provide more robust and additional results.

Given the mixed arguments presented, we expect the relationship between Sustainability performance and stocks return will be positive, given that companies that maintain its social performance and adopt the social responsibility concept in order to be sustainable will also gain good financial performances in the short run and long run. The good management theory explains how the good company management in all aspects led to good financial performance. The slack resources theory explains that good financial performance leads to excess profits that can be used for social activities we propose the following hypothesis:

H1: Firms' sustainability performance held a positive association with its' financial performance

\section{METHODOLOGY}

The final sample in this study consists of 452 companies (209 companies for the year of 2012 and 243 companies for the year 2013). Sustainability-related data are obtained from companies available reports such as annual reports, sustainability reports, corporate social responsibility reports, websites and companies other published documented papers. 
In this study, at first, we use 470 firms listed in the year of 2012-2013 (222 firms for the year 2012 and 248 for the year 2013). However, due to lack of secondary data available (i.e. annual report, sustainability report, historical stocks return, CSR report, financial statement) our final observation decrease to 452 firms (209 for the year of 2012 and 243 for the year of 2013).

The scored firm portfolio contained firms that were listed in the 2-year holding period, while unscored portfolio contained firms that were listed only in 1-year holding period (firms that were included in 2012 but then omitted in 2013, or vice versa). Stock return data are collected from Yahoo. Finance website. Table I below represents the sample composition by industry groups. The trading, services and investments sector represent the substantial majority for the year of 2012 and 2013, while sector agriculture remains as the lowest one. The number of samples came from the agriculture sector increase for more than $44 \%$ between the year of 2012 and 2013, while firms from mining sector were screened out due to low performance. Our final sample grew by $16 \%$ for the 2-year holding period.

Table 1. Sample breakdown by industry

\begin{tabular}{lccccc}
\hline \multirow{2}{*}{ Sector } & \multicolumn{2}{c}{2012} & \multicolumn{2}{c}{2013} & Growth \\
\cline { 2 - 6 } & $\mathrm{N}$ & $(\%)$ & $\mathrm{N}$ & $(\%)$ & $(\%)$ \\
\hline Agriculture & 9 & 4.31 & 13 & 5.35 & 44.44 \\
Mining & 28 & 13.4 & 26 & 10.7 & -7.14 \\
Basic industry \& chemistry & 21 & 10.05 & 29 & 11.93 & 38.10 \\
Miscellaneous industry & 15 & 7.18 & 19 & 7.82 & 26.67 \\
Consumption & 17 & 8.13 & 21 & 8.64 & 23.53 \\
Property \& Real Estate & 32 & 15.31 & 35 & 14.4 & 9.38 \\
Infrastructure, utility and transportation & 18 & 8.61 & 20 & 8.23 & 11.11 \\
Financial & 21 & 10.05 & 25 & 10.29 & 19.05 \\
Trading, services and investment & 48 & 22.97 & 55 & 22.63 & 14.58 \\
\hline Total & 209 & 100 & 243 & 100 & 16.27 \\
\hline
\end{tabular}

In this study, we adopted a methodology developed by Brammer, Brooks \& Pavelin (2006). Firstly, we construct six types of portfolios based on Sustainability Performance (SP) scores, namely top composite portfolio, top social, top environmental, top economic portfolio. We also construct nine types of portfolios based on sector, which are agriculture sector, mining sector, BIC sector, miscellaneous sector, consumption sector, property sector, infrastructure sector, financial sector and trading sector. We build our portfolios equally weighted and assume initial investment on 3 January 2012 for a one or two - year holding period. We compare our portfolios returns to the benchmark (IHSG index).

Next, we construct portfolios based on our SP scores deciles. Each decile contains $20 \%$ of our samples, with decile 1 contains $20 \%$ firms with the lowest SP scores and decile 5 contains $20 \%$ firms with the highest SP scores. We took this procedure to ensure each portfolio we constructed has the same reasonable size.

Then we will conduct a regression between stock returns on SP scores and separately on the three dimensions involved (social, environmental and economic). We take this step to disaggregate the effects of each aspect from SP to stock returns. Lastly, we will run our regression that separates our samples by sectors, due to idea that social responsibility between firms that operate in different fields is different, one firm beneficial activities can be destructive to the other. Hypothesis H1 will be tested by running cross-sectional regression analysis in statistical program STATA.

The regression equation is as follow: 


$$
r_{i, t}=\propto_{0}+\propto_{1} \text { SP Measures } \text { Met, }_{i}+\propto_{2} \text { SIZE }_{i, t-1}+\propto_{3} \text { BETA }_{i, t-1}+\propto_{4} r_{i, t-1}+e_{t}
$$

where:

ri,t $\quad=$ the returns of the stock $\mathrm{i}$ in year $\mathrm{t}$ (each year runs from 3 January);

SP measures $=$ the composite SP scores and its components (social scores, environmental scores, economic scores). Social represents social sustainability score, and environmental represents environmental sustainability score, economic represents economic sustainability score.

size $\quad=$ company' size/natural logarithm of the company's total assets

beta $=$ company's beta

ri,t-1 = momentum/last year return of the company's portfolio

As for our sustainability performance (SP) data, we adopted the methodology developed by Firmialy \& Nainggolan $(2016,2018)$. In their study, They combined several guidelines from Wood (1991), Clarkson (1995), Hopkins (1997), Steg (2003), Dommerholt (2009) to represent SSP framework from academics and SSP framework from KLD, SAM, Calvert, Sustainalytics, FTSE4Good, Vigeo, Oekom, DJSI, GRI, SRI-Kehati, ISO 26000, and IFC to represent social rating agency. They select these rating agencies based on the availability and transparency of data and methodology on the internet and then modified it so it will be better suited to match Indonesia's business environment. In their study, they used the term Corporate Social Performance (CSP), rather than Sustainability Performance (SP). Their final Sustainability Performance Framework (SPF) consisted of three main dimensions which are social, environmental and economic. Overall, their proposed SPF model will cover three dimensions, 17 indicators and 93 sub-indicators.

They divide their framework to strength and concern, whereas the company's strength link with their positive behaviour, whereas the company's concern link with the company's harmful behaviour. The sum of all aspects fell categorized under company's strength can be defined as "strength disclosure score", while the sum of all aspects under company's concern category was translated as "concern disclosure score". The sum of strength and concern score represents composite "total disclosure scores". They employed content analysis on their sub-indicators data as the coding basis and counted each word frequency to measure extensiveness of the information disclosed.

For Sustainability Performance (SP) score estimation, the disclosure score for each item and dimension in the SPF were converted to the range of scale between 1-3, with the score of 3 represent firms that disclose relatively detailed evaluation criteria in the annual report, sustainability report or corporate websites, whereas a score of 2 represent companies that disclose an average amount of information, and finally a score of 1 if it discloses a very brief textual description. Company whose disclose nothing to fall into this latter category.

Furthermore, we re-run the analysis of our regression model on separate sample data based on the sectoral level. We run the analysis furthermore nine times, furthermore represents the analysis on nine sectoral levels in Indonesia Stock Exchange (IDX).

\section{RESULTS AND DISCUSSION}

Table 2 below represents returns from our various portfolios based on SP scores. The top social portfolio contained firms with highest (exceed average) social scores, the top environmental portfolio contained firms with highest environmental scores, the top economic portfolio contained firms with highest economic scores, and top composite 
contained firms with highest sustainability performance (SP) score. Our scores portfolio contained 206 firms, while our unscored portfolio contained 42 firms.

Most of the 1-year returns are all positive for all portfolios, except for top score environmental, agriculture sector, and mining sector. The 1-year return for scored firms sharply underperformed the benchmark index by $17.21 \%$ whereas the un-scored firm returns outperformed the benchmark by $18.64 \%$.

Portfolios of top composites outperformed the index by over than $12.72 \%$. Top environmental portfolio gains negative returns in 1-year investment horizon, as well as agriculture and mining sector. Portfolio containing stocks from the consumption sector grew more than $85 \%$ in 1-year length. The mining sectors performance underperformed the benchmark with and other portfolios we constructed with negative returns more than $30 \%$.

The 2-year returns for most of our portfolios are all positive, except for un-scored firms, agriculture and mining sector. The 2-year return for scored firms outperformed the benchmark index by $6.58 \%$, whereas the un-scored firm returns decreased sharply below the benchmark index by more than $13.9 \%$.

Portfolios of top composites gained negative returns by over $6,5 \%$ compared to the index. Portfolios containing stocks from consumptions sectors and property and real estate sector grew more than $25 \%$ in 2 -year investment horizon. The mining sector shows the slowest performance with negative returns of more than $30 \%$.

Table 2. Returns from various portfolios (\%)

\begin{tabular}{lccc}
\hline & 1-year return $(\%)$ & 2-year return $(\%)$ & Number of firms \\
\hline Scored firms & 1.6 & 0.49 & 206 \\
Unscored firms & 0.1673 & -6.85 & 42 \\
Top score social & 26.83 & 0.24 & 15 \\
Top score environmental & -1.67 & 0.09 & 12 \\
Top score economic & 19.74 & 0.24 & 15 \\
Top score composite & 31.53 & 0.25 & 18 \\
Agriculture sector & -1.3 & -7.98 & 9 \\
Mining sector & -32.71 & -31.84 & 26 \\
Basic industry and chemical & 5.55 & 3.92 & 21 \\
Miscellaneous sector & 14.76 & 14.76 & 15 \\
Consumption sector & 114.03 & 70.67 & 17 \\
Property and real estate sector & 50.75 & 33.55 & 32 \\
Infrastructure sector & 53.29 & 23.91 & 18 \\
Financial sector & 33.69 & 18.31 & 21 \\
Trading. services and investment & 45.54 & 28.32 & 47 \\
Benchmark (IHSG) & 18.81 & 7.07 & 450 \\
\hline
\end{tabular}

Our findings are consistent with our hypothesis and previous results by Boaventura, Da Silva \& De Mello (2012). We found an empirical evidences on the positive relationship of companies social performance and financial performance in the long run. We also found similar evidences on the relationship between companies social performance and financial performance in the short run, similar to previous findings of Brammer, Brooks \& Pavelin (2006).

Next, we will examine our portfolio based on deciles of SP scores that can be seen below in Table 3. Portfolio social-decile 1 contains $20 \%$ of firms with the lowest social scores, and so on, while social-decile 5 contains $20 \%$ of firms with the highest social scores. Portfolio environmental-decile 1 contains $20 \%$ of firms with the lowest 
environmental scores, while environmental-decile 5 contains $20 \%$ of firms with the highest environmental scores.

Portfolio economic-decile 1 contains $20 \%$ of firms with the lowest economic scores, while portfolio economic-decile 5 contains $20 \%$ of firms with the highest economic scores. Portfolio composite decile-1 contains $20 \%$ of firms with the lowest sustainability performance scores, while portfolio composite decile-5 contains $20 \%$ of firms with the highest sustainability performance scores.

Environmental and economic portfolios shown that with an increase in SP scores, stocks returns also increase simultaneously, whether it is in the 1-year or 2-year horizon. Composites and social portfolios also shown a positive increasing until decile 4 , then slightly decline by over than $9 \%$ for the $20 \%$ of firms with the highest scores. In this sense, it is safely said that sustainability performance of the firms' ability to give a positive contribution to the stock return, by increasing its sustainability certainty (real strength), thus decreasing its sustainability uncertainty (adverse concern).

Table 3. Returns from various portfolios based on decile of sustainability performance (SP) scores $(\%)$

\begin{tabular}{lrrrr}
\hline & Social & Environmental & Economic & Composite \\
\hline Panel A - 1 year returns & & & & \\
Decile 1 & -39.47 & -40.69 & -42.34 & -36.98 \\
Decile 2 & -1.67 & -3.63 & -5.74 & 3.67 \\
Decile 3 & 22.45 & 17.09 & 12.53 & 34.76 \\
Decile 4 & 60.47 & 42.30 & 36.14 & 43.55 \\
Decile 5 & 17.84 & 44.54 & 59.02 & 14.61 \\
\hline Panel B - 2 year returns & & & & \\
Decile 1 & -4.69 & -4.91 & -5.14 & -4.51 \\
Decile 2 & 0.25 & -0.56 & -0.79 & 0.32 \\
Decile 3 & 2.30 & 1.27 & -9.92 & 3.55 \\
Decile 4 & 11.71 & 4.27 & 3.59 & 10.02 \\
Decile 5 & 2.08 & 9.73 & 11.11 & 2.08 \\
\hline
\end{tabular}

The next step will discuss on regression results between stocks returns and sustainability performance. Table 4 below represent regressions results on each component of sustainability performance (SP) scores, namely social sustainability score, environmental sustainability score and economic sustainability score. Social represents social sustainability score, and environmental represents environmental sustainability score, economic represents economic sustainability score. Size represents the natural logarithm of total asset, and beta represents the company's exposures to market risk. Significance level of $5 \%$ and $10 \%$ level were denoted by the $\operatorname{star}\left({ }^{*}\right)$ and $(* *)$, respectively.

SP is positively significant to stocks return at the $10 \%$ level, with an increase of 1 point in the SP score leads to an increase in return for $0,006 \%$ per year. Our findings are consistent with our hypothesis and previous results by Brammer, Brooks \& Pavelin (2006). The phenomena may occur because of companies' capability to maintain its' social performance, and companies will get many benefits from this acts as well, such as minimizing potential conflicts with shareholders, enhancing companies' reputational image in public eyes, and increasing companies' productivity.

Environmental scores are negatively significant to stocks return at the $10 \%$ level, with an increase in environmental scores leads to a decrease in return for $0,001 \%$ per year, consistent with our hypothesis and previous results by Brammer, Brooks \& Pavelin (2006). 
The phenomena may be related to companies' high environmental expenditures that affected companies' profit, thus decreasing its' performances. Companies' beta is positively significant to return at 5\% level, with an increase of 1-point in companies' beta leads to an increase in return for $1,999 \%$ per year and $2,105 \%$ per two years holding period. The findings are consistent with our hypothesis and the basic concept of "higher risk, higher return".

Momentum is negatively significant at 5\% level, with an increase of 1-point in momentum score leads to a decrease in return for $6,867 \%$ per year, consistent with our hypothesis and previous results by Brammer, Brooks \& Pavelin (2006).

Our model able to describe around $80 \%$ of the variation between SP and portfolios' stocks return with our selected independent variables, and the other $20 \%$ of the variation can be explained by other variables related to the stocks return and SP measures. Regression on returns on each separate measure of SP for 1-year and 2-year holding period can be seen in Table 4 .

Table 4. Regression of returns on each separate measures of sustainability performance (SP) for 1-year and 2-year holding period

\begin{tabular}{|c|c|c|c|c|c|c|c|c|}
\hline & \multicolumn{4}{|c|}{ 1-Year } & \multicolumn{4}{|c|}{ 2-Year } \\
\hline & (1) & (2) & (3) & (4) & (1) & (2) & (3) & (4) \\
\hline CSP & $\begin{array}{r}0.003 \\
(0.291)\end{array}$ & & $\begin{array}{r}0.006 * * * \\
(0.094)\end{array}$ & & $\begin{array}{r}0.001 \\
(0.7459)\end{array}$ & & $\begin{array}{r}0.001 \\
(0.1662)\end{array}$ & \\
\hline Social & & $\begin{array}{r}-0.003 \\
(0.632)\end{array}$ & & $\begin{array}{l}0.003 \\
(0.19)\end{array}$ & & $\begin{array}{r}0.001 \\
(0.6049)\end{array}$ & & $\begin{array}{r}0.001 \\
(0.6373)\end{array}$ \\
\hline Environmental & & $\begin{array}{r}-0.001 \\
(0.247)\end{array}$ & & $\begin{array}{r}-0.001 * * \\
(0.057)\end{array}$ & & $\begin{array}{r}0.001 \\
(0.5123)\end{array}$ & & $\begin{array}{r}-0.001 \\
(0.17)\end{array}$ \\
\hline Economic & & $\begin{array}{r}-0.002 \\
(0.201)\end{array}$ & & $\begin{array}{r}-0.001 \\
(0.165)\end{array}$ & & $\begin{array}{r}-0.001 \\
(0.7331)\end{array}$ & & $\begin{array}{r}-0.001 \\
(0.1728)\end{array}$ \\
\hline Size & & & $\begin{array}{r}-0.001 \\
(0.142)\end{array}$ & $\begin{array}{r}-0.001 \\
(0.136)\end{array}$ & & & $\begin{array}{r}3.4 \times 10^{-09} \\
(0.637)\end{array}$ & $\begin{array}{r}3 \times 10^{-09} \\
(0.7005)\end{array}$ \\
\hline Beta & & & $\begin{array}{l}1.938^{*} \\
(0.003)\end{array}$ & $\begin{array}{l}1.999^{*} \\
(0.002)\end{array}$ & & & $\begin{array}{r}2.092 * \\
(0.0009)\end{array}$ & $\begin{array}{r}2.105^{*} \\
(0.0008)\end{array}$ \\
\hline Momentum & & & $\begin{array}{c}-6.877 * \\
(0.000)\end{array}$ & $\begin{array}{r}-6.867 * \\
(0.000)\end{array}$ & & & $\begin{array}{r}-0.00569 \\
(0.6646)\end{array}$ & $\begin{array}{r}-0.00547 \\
(0.6787)\end{array}$ \\
\hline Coefficient & $\begin{array}{l}0.194^{*} \\
(0.000)\end{array}$ & $\begin{array}{l}0.210^{*} \\
(0.000)\end{array}$ & $\begin{array}{l}0.211^{*} \\
(0.000)\end{array}$ & $\begin{array}{l}0.226^{*} \\
(0.000)\end{array}$ & $\begin{array}{l}0.197 * \\
(0.000)\end{array}$ & $\begin{array}{l}0.199^{*} \\
(0.000)\end{array}$ & $\begin{array}{c}0.198 * \\
(0.000) \\
\end{array}$ & $\begin{array}{c}0.201^{*} \\
(0.000) \\
\end{array}$ \\
\hline R-Square & - & - & 0.805 & 0.804 & 0.000 & 0.001 & 0.298 & 0.301 \\
\hline
\end{tabular}

Our findings confirmed the previous result suggested by Galema, Plantings \& Scholtens (2008). In their study, they confirmed ae positive relationship between the social performance of the firms with stocks returns based on 14-year data observation. They found that social employee dimension gave the highest positive relationship to the stock return. The phenomena possibly related to the market slow response to the social information that considered as the intangible capital and therefore harder to valuate rather than the tangible capital.

In short year span, the environmental performance gave a positive relationship to the stock return, aligned with previous results suggested by Odia \& Imaghe (2015). In their study, they confirmed the positive relationship between environmental performance and companies financial performance with Structural Equation Modelling (SEM) modelling technique based on short term data (less than a year observation time). The phenomena translated as companies' good signal of "eco-efficiency" to the market. However, this raises other issues to discuss further. Could it be that the signal is mixed? Is there possibly any conflict of interest that motivated the company to disclose such 
information to the public? This two questions may serve as new direction on future research.

Our final step will examine the relationship between separate SP measures to stocks return in 1 and 2 years holding period per sector, and the result is shown in Table 5 below. Social represents social sustainability score, and environmental represents environmental sustainability score, economic represents economic sustainability score. Significance level of $5 \%$ and $10 \%$ level were denoted by star $(*)$ and (**), respectively.

At 1-year holding period, social scores are negatively significant at $10 \%$ level in the miscellaneous sector, real estate and property sector and financial sector, while at 2 year holding period, social scores are negatively affected the miscellaneous sector and financial sector at 5\% level. Environmental scores are positively significant at 5\% level in the infrastructure sector, with an increase of 1-point in environmental scores leads to $0,129 \%$ increase in returns per year. However, the relationship between environmental scores and stocks return show different results for the financial sector, compared to the infrastructure sector.

Environmental scores are negatively significant at $10 \%$ level, with an increase of 1-point in environmental scores leads to $0,267 \%$ decrease in stocks return per year, and $0,648 \%$ decrease in stocks return per two-year holding period. At 1-year holding period, economic scores are negatively significant at 5\% level in real estate, and property sector, infrastructure sector, financial sector, with an average decrease in stocks return around $0,174 \%$ per 1-point increase in economic scores.

At two year holding period, economic scores are negatively significant at 5\% level in primary industry, and chemical sector, real estate and property sector, infrastructure sector and financial sector, with an average decrease in stocks, return around 0,518\% per 1-point increase in economic scores. However, the relationship between stocks return and economic scores are different for the agriculture sector, compared to the other sectors.

Economic scores in the agriculture sector are positively significant at the $10 \%$ level, with an increase of 1-point in economic scores leads to $0,509 \%$ increase of stocks return per year, and $0,959 \%$ increase of stocks return per two years.

Our findings may be related to companies' in the agricultural sector are more sensitive to their environmental performance rather than its social performance (we can observe this from each variable parameter estimates), thus adopt the social responsibility concept in order to be sustainable. Since we use stocks return in this research as a proxy for financial performance measures, it is safe to say that the companies' strategy is in line with ethical investors who based their investing preference to social/ethical criteria.

In this sense, it is safely said that sustainability performance of the firms' ability to give a positive contribution to the stock return, by increasing its sustainability certainty (positive strength), thus decreasing its sustainability uncertainty (negative concern), or specifically firms' idiosyncratic risk. Overall, our study supports global views of SP as a positive indicator to the firms' financial performance and hence result in further recommend on an increase investment in SP, specifically environmental dimension in short year time span (less than 1 years) and economic dimension in long year time span (more than 2 years).

Our findings stressed out the importance of positive relationships between stock return and social sustainability performance, furthermore realizing the main benefit that investors will get by carefully screening which ethical stocks "worth" to invest. This finding is aligned with the good management theory that explains how good company 
management in all aspects can lead to good financial performance. Our final finding stressed out the importance of positive relationships between stocks return and Social Sustainability Performance.

Our findings agree with the good management theory that explains how good company management in all aspects can lead to good financial performance. However, due to limited time, our research process samples only limited to 2 years of data holding mutual fund. Future research may be able to extend the time length of the research process to examine the effect of SP with stocks thoroughly return, especially the potential leveraging effect of corporate efficiency as a moderator variable between the corporate sustainability performance and financial performance. Future research also stresses out the importance to evaluate determinants of Sustainability Performance (SP) in Indonesia, as well as evaluating the relationship between SP and CFP at the mutual fund level.

Table 5. Regression of returns on each separate measures of sustainability performance (SP) For 1-year and 2-year holding period per sector

\begin{tabular}{|c|c|c|c|c|c|c|c|c|c|c|}
\hline & $\alpha 1$ & $\begin{array}{r}p- \\
\text { value }\end{array}$ & $\alpha 2$ & $\begin{array}{c}p- \\
\text { value }\end{array}$ & $\alpha 3$ & $\begin{array}{r}p- \\
\text { value }\end{array}$ & $\alpha 0$ & $\begin{array}{r}p- \\
\text { value }\end{array}$ & $N$ & $\begin{array}{r}R- \\
\text { square }\end{array}$ \\
\hline \multicolumn{11}{|c|}{ 1-year holding return } \\
\hline Agriculture & $-0,041$ & 0,582 & $0,5095 *$ & 0,051 & 0,154 & 0,419 & $-0,1452 * *$ & 0,043 & 9 & 0,388 \\
\hline Mining & 0,024 & 0,841 & 0,012 & 0,865 & $-0,294$ & 0,124 & 0,007 & 0,898 & 26 & 0,091 \\
\hline $\begin{array}{l}\text { Basic Industry and } \\
\text { Chemical }\end{array}$ & 0,030 & 0,476 & $-0,288$ & 0,220 & $-0,192$ & 0,230 & $0,1155^{* *}$ & 0,021 & 21 & 0,310 \\
\hline Miscellaneous & $-0,1286^{*}$ & 0,057 & $-0,165$ & 0,273 & 0,308 & 0,313 & 0,160 & 0,141 & 15 & 0,264 \\
\hline Consumption & 0,050 & 0,276 & $-0,304$ & 0,381 & 0,051 & 0,755 & 0,098 & 0,372 & 17 & 0,020 \\
\hline $\begin{array}{l}\text { Real Estate and } \\
\text { Property }\end{array}$ & $-0,1406^{*}$ & 0,061 & $-0,1964 * * *$ & 0,004 & 0,036 & 0,671 & $0,1586 * * *$ & 0,008 & 32 & 0,171 \\
\hline Infrastructures & 0,014 & 0,701 & $-0,3694 * * *$ & 0,000 & $0,1292 * *$ & 0,043 & $0,0963 * *$ & 0,010 & 18 & 0,493 \\
\hline Financial & $-0,006$ & 0,822 & 0,056 & 0,824 & $-0,084$ & 0,113 & 0,024 & 0,643 & 21 & 0,184 \\
\hline $\begin{array}{l}\text { Services, trading } \\
\text { and investment }\end{array}$ & $-0,003$ & 0,936 & 0,107 & 0,114 & $-0,1163 * * *$ & 0,002 & 0,017 & 0,472 & 47 & 0,037 \\
\hline \multicolumn{11}{|c|}{ 2-year holding return } \\
\hline Agriculture & $-0,059$ & 0,699 & $0,9588 * *$ & 0,016 & 0,164 & 0,669 & $-0,2543 * *$ & 0,018 & 9 & 0,411 \\
\hline Mining & 0,144 & 0,513 & $-0,064$ & 0,623 & $-0,278$ & 0,267 & $-0,056$ & 0,610 & 26 & 0,037 \\
\hline $\begin{array}{l}\text { Basic Industry and } \\
\text { Chemical }\end{array}$ & 0,119 & 0,419 & $-0,9609 * *$ & 0,026 & $-0,252$ & 0,293 & $0,2381 * *$ & 0,037 & 21 & 0,257 \\
\hline Miscellaneous & $-0,2847 * *$ & 0,020 & $-0,354$ & 0,169 & 0,602 & 0,205 & $0,3593 *$ & 0,079 & 15 & 0,276 \\
\hline Consumption & $-0,004$ & 0,952 & $-0,599$ & 0,418 & 0,161 & 0,516 & 0,253 & 0,319 & 17 & 0,028 \\
\hline $\begin{array}{l}\text { Real Estate and } \\
\text { Property }\end{array}$ & $-0,282$ & 0,146 & $-0,2824 * *$ & 0,042 & $-0,006$ & 0,977 & $0,3065 * *$ & 0,028 & 32 & 0,132 \\
\hline Infrastructures & 0,031 & 0,706 & $-0,6735 * * *$ & 0,000 & 0,115 & 0,615 & $0,2152 * *$ & 0,029 & 18 & 0,290 \\
\hline Financial & 0,017 & 0,786 & $-0,125$ & 0,841 & $-0,136$ & 0,273 & 0,101 & 0,448 & 21 & 0,113 \\
\hline $\begin{array}{l}\text { Services, trading } \\
\text { and investment }\end{array}$ & $-0,045$ & 0,410 & 0,067 & 0,721 & $-0,149$ & 0,134 & 0,085 & 0,134 & 47 & 0,031 \\
\hline
\end{tabular}

Note: $\alpha 0$ represent the portfolio' intercept; $\alpha 1-3$ represent company slopes; $p$-value represents the p-value for each independent variables toward dependent variables in our equation; star $(*)$ represent significance level higher than $95 \%$ confidence interval, and star (**) represent significance level between $90 \%-95 \%$ confidence interval.

\section{CONCLUSION AND RECOMMENDATIONS}

\section{Conclusion}

This study presents to answer a big question regarding the growing trends of sustainability and financial performance. We designed the paper with the aim to determine the relationship between Sustainability Performance (SP) of the firm to the financial performance, or in this case, the stock return was chosen as the observed indicator for financial performance specifically, in portfolio level. The final sample evaluated consists of 452 companies (209 companies for the year of 2012 and 243 companies for the year 2013). We built our methodology to evaluate the relation between SP and stocks return by following Brammer, Brooks \& Pavelin (2006). While 
the Sustainability Performance (SP) scores were developed based on references by Firmialy and Nainggolan $(2016,2018)$.

There are two main essential findings in the study. Firstly, based on the result of sustainability performance measurement, all firms' shows an increase in their social and economic performance and a decrease in their environmental scores. Social, environmental and economic performances are varied across industries.

Secondly, environmental sustainability and economic sustainability portfolios have shown that with an increase in sustainability scores, stocks return also increase simultaneously, whether it is in the 1-year or 2-year horizon. The same evidence was gained from composite and social sustainability portfolios, both increases in the composite sustainability performance and social sustainability performance show increasing positive movement to the firm stock return. Sustainability performance scores and Beta are positively significant to stocks' return, while momentum is negatively significant to stocks return.

In this sense, it is safely said that sustainability performance of the firms' ability to give a positive contribution to the stock return, by increasing its sustainability certainty (positive strength), thus decreasing its sustainability uncertainty (negative concern), or specifically firms' idiosyncratic risk. Overall, our study supports global views of SP as a positive indicator to the firms' financial performance and hence result in further recommend on an increase investment in SP, specifically environmental dimension in short year time span (less than 1 years) and economic dimension in long year time span (more than 2 years).

Our findings stressed out the importance of positive relationships between stock return and social sustainability performance, furthermore realizing the main benefit that investors will get by carefully screening which ethical stocks "worth" to invest. This finding is aligned with the good management theory that explains how good company management in all aspects can lead to good financial performance. Our final finding stressed out the importance of positive relationships between stocks return and social sustainability performance.

Our findings agree with the good management theory that explains how good company management in all aspects can lead to good financial performance. However, due to limited time, our research process samples only limited to 2 years of data holding mutual fund. Future research may be able to extend the time length of the research process to examine the effect of SP with stocks thoroughly return, especially the potential leveraging effect of corporate efficiency as a moderator variable between the corporate sustainability performance and financial performance. Future research also stresses out the importance to evaluate determinants of Sustainability Performance (SP) in Indonesia, as well as evaluating the relationship between SP and CFP at the mutual fund level.

\section{Recommendations}

Our findings practical implication focused on the benefit of "Sustainability Investing" and furthermore, realizing the main benefit that investors will get by carefully screening which ethical stocks "worth" to invest. Findings of this study confirmed the notion of heterogenous sustainability performance within Indonesian firms, on a sectoral level. We also found pieces of evidence on the positive direction of an increase of social and economic performance to stock return. Meanwhile, environmental sustainability performance shows otherwise. 
Also, the study contributes to the theoretical context of sustainability and firm financial performance in the context of developing countries, specifically in Indonesia, based on the guidances of stakeholder theory as the main principle found in the study.

The practical contribution of this study is significant for corporate managers on the importance of maintaining the firms' SP as a way to "prosper in the long term". Secondly, the practical contribution of this study stressed on the importance of corporate managers to invest in three dimensions of SP disaggregate and further integrate it into companies strategy as an essential risk management tool.

However, this result gave a unique signal that further recommended to us to identify whether there is an effect of "greenwashing" or specific "eco-reputational illusion" occurred. Thus recommendation served as our principal, further direction for future research. The second recommendation of this study suggests that there is a conflict of suspicions on whether the manager may act to their benefit by creating the "eco-reputational illusion" as suggested by the agency conflict and signalling theory. The second recommendation further discusses in our next topic of research.

\section{REFERENCES}

Alexander, G.J. \& R.A. Buchholz. (1978). Corporate Social Responsibility And Stock Market Performance. Academy Of Management Journal, 21(3), 479-486.

Artiach, T., Lee \& Nelson, D. (2010). The Determinants Of Corporate Sustainability Performance. Accounting And Finance, 50(1), 31-51.

Boaventura, J.M.G., Da Silva, R.S., \& De Mello, R.B. (2012). Corporate Financial Performance And Corporate Social Performance Methodological Development And The Theoretical Contribution Of Empirical Studies. R.Cont.Fin Usp, Sao Paulo, 23(60), 232-245.

Boutin-Dufresne, F., \& P. Savaria. (2004). Corporate Social Responsibility and Financial Risk. The Journal of Investing 13(1), 57-66.

Brammer, S., Brooks, S. \& Pavelin, S. (2006). Corporate Social Performance And Stock Returns: Uk Evidence From Disaggregate Measures. Financial Management, 35(3), 97-116.

Brammer, S. \& Millington, A. (2008). Does It Pay To Be Different? An Analysis Of The Relationship Between Corporate Social And Financial Performance. Strategic Management Journal, 29(12), 1325-1343.

Brammer, S. \& Pavelin, S. (2005). Corporate Reputation And Social Performance : The Importance Of Fit. Journal Of Management Studies, 43(3), 435-455.

Cheng, B., Ioannou, I., \& Serafeim, G. (2014). Corporate social responsibility and access to finance. Strategic Management Journal, 35(1), 1-23.

Clarkson, M.B.E. (1995). A Stakeholder Framework For Analyzing And Evaluating Corporate Social Performance. Academy Of Management Review, 20(1), 92-117.

De, I., \& M. Clayman. (2010) . Are All Components of ESG Score Equally Important?. NYSSA Finance Professionals' Post, July 2010.

Dhaliwal, D., Oliver, L., Tsang, A., \& Yang, Y. (2011). Voluntary nonfinancial disclosure and the cost of equity capital: The initiation of corporate social responsibility reporting. Accounting Review, 86(1), 59-100.

Dhaliwal, D., Radhakrishnan, S., Tsang, A., \& Yang, Y. (2012). Nonfinancial disclosure and analyst forecast accuracy: International evidence on corporate social responsibility (CSR) disclosure. Accounting Review, 87(3), 723-759.

Dommerholt, Egbert (2012). Validity And Comparability Of The Sam And Kld Screening Instruments. The Dovenschmidt Quarterly, 1, 45-64. 
Dravenstott, J., \& N. Chieffe. (2011) . Corporate Social Responsibility: Should I Invest for It or Against It?. The Journal of Investing, 20(3), 108-117.

Fabozzi, F., K. C. Ma, \& B. Oliphant. (2008) . Sin Stock Returns. The Journal of Portfolio Management, 35(1), 82-94.

Fauzi, H., Mahoney, L. \& Rahman, A. (2007). Institutional Ownership And Corporate Social Performance Empirical Evidence From Indonesian Companies. Social And Environment Accounting, 1(2), 334-347.

Fauzi, H., Mahoney, L. \& Rahman, A.A. (2007). The Link Between Corporate Social Performance and Financial Performance Evidence From Indonesian Companies. Social And Environmental Accounting, 1(1), 149-159.

Fauzi, H. (2008). The Determinants Of The Relationship Of Corporate Social Performance and Financial Performance Conceptual Framework. Social And Environmental Accounting, 2, 1-32.

Fauzi, H., \& Idris, K.M. (2009). The Relationship Of CSR and Financial Performance: New Evidence From Indonesian Companies. Social And Environmental Accounting, 3(1), 66-87.

Firmialy, S. D., \& Nainggolan, Y. A. (2018). Constructing the ideal SRI (sustainability reporting index) framework for Indonesian market: combined perspectives from rating agencies, academics, and practitioners. Social Responsibility Journal, 15(5), 573-596

Firmialy, S. D., (2016). Corporate Social Performance and Stock Returns: Framework Development And Evaluation : Case Of Indonesia Market (Unpublished master's thesis). School of Business and Management, Bandung Institute of Techology (Institut Teknologi Bandung), West Java, Indonesia.

Fulton, M., B. Kahn, \& C. Sharples. (2012). "Sustainable Investing: Establishing LongTerm Value and Performance." In Report, Climate Change Advisors. Deutsche Bank.

Galema, R., Plantings, A., \& Scholtens, B. (2008). The Stocks At Stake: Return And Risk In Socially Responsible Investment. Journal Of Banking And Finance, 32(12), 2646-2659.

Hong, H., \& Kacperczyk, M. (2009). The price of sin: The effects of social norms on markets. Journal of Financial Economics, 93(1), 15-36.

Hopkins, M (1997). Defining Indicators To Assess Socially Responsible Enterprises. Futures, 29(7), 581-603.

Jo, H., \& Na, H. (2012). Does CSR reduce firm risk? Evidence from controversial industry sectors. Journal of Business Ethics, 110(4), 441-456.

Mishra, S., \& Modi, S. (2013). Positive and negative corporate social responsibility, financial leverage, and idiosyncratic risk. Journal of Business Ethics, 117(2), 431-448.

Odia, J. O., \& Imagbe, V. U. (2015). Corporate Social and Environmental Disclosures, Corporate Social and Environmental Performance and Corporate Financial Performance in Nigeria: A Simultaneous Equation Approach. International Journal of Management, 5(9), 615-627.

Orlitzky, M., Schmidt, F., \& Rynes, S., (2003). Corporate Social And Financial Performance Meta-Analysis. Organization Studies, 24(3), 403-411.

Rais, S., \& Goedegebuure R.V., (2009). Corporate Social Performance And Financial Performance The Case Of Indonesian Firms In The Manufacturing Industry. Problems And Perspectives In Management,7(1), 1-10. 
Statman, M., \& D. Glushkov. (2009). The Wages of Social Responsibility. Financial Analysts Journal. 65(4), 33-46.

Steg, L., Vlek, C., Lindenberg, S., Groot, T., Moll, H., Schoot Uiterkamp, T., \& Van Witteloostuijn, A. (2003). Towards a comprehensive model of sustainable corporate performance. Groningen: Ubbo Emmius Fund

Ullmann, A.A. (1985). Data In Search Of A Theory: A Critical Examination Of Economic Performance On U.S. Firms, Academy Of Management Review, 10, 540-957.

Vance, S.C. (1975). Are Socially Responsible Corporations Good Investment Risks? Management Review, 64, 18-24

Wood, D.J., (1991). Corporate Social Performance Revisited, Academy Of Management Review, 16, 691-718. 